\title{
Characteristics of Sexual Violence Against Adolescent Girls: A 10 Years' Retrospective Study of 73I Sexually Abused Adolescents
}

\author{
Giussy Barbara $\mathbb{D}^{1,2}$, Valentina Albertini ${ }^{3}$, Veronica Maria Tagi ${ }^{4}$, Lidia Maggioni ${ }^{5}$, \\ Maria Carlotta Gorio ${ }^{6}$, Cristina Cattaneo ${ }^{5}$, Fabio Parazzini ${ }^{2}$, Elena Ricci $\mathbb{D}^{2}$, Laura Buggio (D)', \\ Alessandra Kustermann' \\ 'Gynecological Unit and SVSeD, Service for Sexual and Domestic Violence, Fondazione IRCCS Ca' Granda Ospedale Maggiore Policlinico, Milan, Italy; \\ ${ }^{2}$ Department of Clinical Sciences and Community Health, University of Milan, Milan, Italy; ${ }^{3}$ Department of Emergencies, ASST Grande Ospedale \\ Metropolitano Niguarda, Milan, Italy; ${ }^{4}$ Department of Paediatrics, University of Chieti, Chieti, Italy; ${ }^{5}$ Department of Biomedical Science, Legal \\ Medicine Section, University of Milan, Milan, Italy; ${ }^{6}$ Department of Clinical and Biomedical Sciences Luigi Sacco, University of Milan, Milan, Italy
}

Correspondence: Laura Buggio, Gynecological Unit and SVSeD, Fondazione IRCCS Ca' Granda Ospedale Maggiore Policlinico, Via Commenda, I2, Milan, 20122, Italy, Tel +39025503 2917, Fax +3902 50320264, Email buggiolaura@gmail.com

Introduction: Sexual violence against young girls is a pervasive multifaceted phenomenon which embraces several different forced sexual acts, including attempted and/or completed rape, sexual coercion and harassment, and sexual contact with force or threat of force. The aim of this study is to evaluate the characteristics of sexual violence in adolescent girls, by a retrospective analysis of 731 consecutive cases of sexually abused girls.

Materials and Methods: We analyzed demographic characteristics, risk factors for rape, and the eventual subsequent presence and type of ano-genital lesions.

Results: We found that sexual violence with penetration was perpetrated in $591(80 \%)$ cases. Vulnerability factors related with a major risk of rape were age $>17$ years old and consumption of alcohol and/or other drugs. About 196 (55\%) victims had at a least one genital lesion.

Conclusion: A prompt identification of red flags of sexual violence may help physicians in suspecting and managing cases of sexual assault in adolescent girls, even in the absence of typical lesions.

Keywords: sexual violence, gender violence, rape, adolescent, genital lesions

\section{Introduction}

Sexual violence (SV) against young girls is a pervasive multifaceted phenomenon which embraces several different forced sexual acts, including attempted and/or completed rape, sexual coercion and harassment, and sexual contact with force or threat of force. As recognized by several organizations, SV represents a major health problem, as well as a widespread violation of human rights. ${ }^{1,2}$

SV could occur in child maltreatment (defined by the World Health Organization as any abuse and neglect that occurs to children under 18 years of age), which involve also physical and/or emotional ill-treatment, neglect, negligence and/or other exploitation. ${ }^{3}$ Moreover, SV may often occur in intimate relationship, ${ }^{4}$ as part of domestic violence, which is one of the most common forms of violence against women and includes physical, sexual, and emotional abuse as well as controlling behaviors by an intimate partner. ${ }^{5}$

Specifically, the estimated proportion of adolescent who had survived SV is not negligible. The World Health Organization (WHO) indicated that for almost one-third of adolescent girls the first sexual experience is reported as being forced; ${ }^{1}$ other authors reported that about $12 \%$ to $25 \%$ of girls under the age of 18 have experienced in their life some form of SV. ${ }^{6}$ An Italian national survey showed that about $10 \%$ of the interviewed women reported having suffered 
from some form of SV before the age of $16 .{ }^{7}$ According to literature, adolescents are more likely to be involved in sexual misconducts and crimes than any other age group. ${ }^{8-10}$ The National Crime Victim Survey pointed out that adolescent girls are four times more likely than the general population to report SV. ${ }^{11}$

Gender violence has several negative repercussions on women's physical and mental health. ${ }^{9}$ Specifically, SV in adolescence could have particularly harmful and detrimental consequences, as it was reported that unwanted sexual experiences, especially if reiterated and prolonged, may affect the dynamic brain development and influence structural changes in the brain, leading to a dysregulation of the neurobiological responses to external negative stimuli and to an impairment of the development of individual capabilities and resources essential for the psychological well-being in adult life. ${ }^{12-16}$

Several vulnerability factors are reported to be associated with an increased risk of SV. In particular young age, a past history of rape or other forms of SV, living in foster care, the presence of physical and/or mental disability, abuse of alcohol or other drugs, and experiencing an abusive intimate relationship expose to higher risk of sexual victimization. ${ }^{17}$

Taken together, all these data support the hypothesis that adolescence is a period of increased vulnerability to SV, both at home and outside the family. The psychological repercussions represent significant and ongoing harm. A recent systematic review focusing on different types of psychosocial interventions for adolescent and adult victims of SV highlighted a gap in the evidence for effectiveness of such interventions. Some weak evidence is reported only as regard to cognitive behavioral therapy (CBT) based interventions, especially trauma processing. ${ }^{18}$

Despite the higher risk of sexual victimization, adolescence has often been overlooked in global health and social policy. ${ }^{14}$ Much research has been published on SV against adult women or children, ${ }^{19-25}$ but limited studies specifically focused on SV in adolescence. ${ }^{20,26,27}$ Several similarities may exist between SV which occurred in adolescence or in other periods of life, ${ }^{27}$ although it is reasonable to suppose that some vulnerability factors, characteristics of the SV and features of SV-related genital lesions occurred in adolescence may substantially differ from those related to a SV occurring at an older age or during childhood. ${ }^{25}$ In addition, to our knowledge no studies have systematically investigated the presence of specific characteristics of SV as well as the presence and types of ano-genital lesions in large series of adolescent girls.

Assuming this background, we conducted a retrospective study on a large population sample of adolescent girls referring for SV to a referral rape-center, aimed at providing a broader understanding on the phenomenon of SV in adolescence focusing on several specific aspects: 1) the characteristics of the SV; 2) the typology of perpetrators; 3) the presence and type of vulnerability factors; 4) features of the ano-genital lesions caused by the violence.

\section{Materials and Methods}

The current study is part of a larger research on SV against adolescent girls. The investigation was conducted at the Service for Sexual and Domestic Violence (SVSeD), Department of Women's and Children's Health, Fondazione IRCCS Ca' Granda Ospedale Maggiore Policlinico, Milan, Italy. Local Institutional Review Board approval for the study was obtained (Comitato Etico Milano Area 2). All women accessing to SVSeD, at the time of the clinical/forensic evaluation for $\mathrm{SV}$, are routinely requested to sign written informed consent to clinical/gynecological procedures, documentation of injuries (including pictures of lesions), collection of forensic specimens as well as to authorize researchers to review their medical records and use data for research, ensuring data confidentiality.

For the current retrospective research, the study sample was obtained analyzing all medical records of female victims of SV aged 10 to 19 who referred to SVSeD in a period of 10 years (2006-2016). Data obtained from consulting medical records were reported in a digital data set.

As the research question was to provide a broad perspective on the characteristics of SV in adolescence, in particular as regard to the characteristics of the SV (for example penetrative or not-penetrative acts), the typology of perpetrators, the presence and type of vulnerability factors, and the features of the ano-genital lesions, for each medical record of girls aged 10 to 19 who accessed the Center for SV we recorded the following variables:

- victims' age and nationality, 
- presence of vulnerability factors as described in literature ${ }^{17}$ (such as previous SV, alcohol and/or other drug abuse, exposure to domestic violence and child maltreatment, psychiatric and cognitive disorders, history of pregnancies or abortions, prostitution, homeless, adoption/Community housing, physical diseases involving disability, criminal records ${ }^{17}$ ),

- characteristics of perpetrators of violence (such as the number of perpetrators and their relationship with the victim),

- characteristics of the SV (such as places where SV occurred, time passed between the SV and the admission to SVSeD, types of forced sexual acts, modality of penetration, condom use),

- types and distribution of genital and extra-genital lesions caused by the SV.

Data were entered from SVSeD records into Microsoft Excel (version 15.33; Microsoft, Redmond, WA) and statistical analyses were performed using the SAS/STAT statistical package (version 9.4; SAS Institute INC., Cary, North Carolina, USA). Descriptive statistics were achieved for demographic and social data; continuous variables are presented as means with standard deviations $(\mathrm{M} \pm \mathrm{SD}$ ), while categorical data as percentages and frequencies. Associations between risk factors and outcomes of interest were evaluated using the logistic regression; the strength of association was measured by odds ratio (OR) and $95 \%$ confidence interval $(95 \% \mathrm{CI}) . \mathrm{P}<0.05$ was considered statistically significant. Raw data have been further evaluated by multiple statistical regressions; two different multivariate analyses were performed, using as independent variables, as follows: sexual assault with penetration and the presence of genital trauma. In the model were included only those variables which had a statistical association at the univariate analyses $(\mathrm{p}<0.05)$.

\section{Results}

\section{Demographic and Social Characteristics of Victims and Perpetrators}

A total of 976 adolescents between the age of 10-19 referred to SVSeD in the study period; $731(74.9 \%)$ of them were included in the current study, whereas $245(25.1 \%)$ were excluded because they were male $(n=59,6 \%)$, or because the history of the violence was not pertinent with our research or due to missing data $(n=186,20 \%)$.

Demographic and social characteristics of the population under study are presented in Table 1 . The mean age of the sample was $15.5 \pm 2.4$ years, and $576(79 \%)$ of the girls were aged $14-19$ years old.

More than half of the population examined $(404,55.3 \%)$ was represented by Italian girls, whereas the second most represented region of origin was Latin America (167, 22.8\%). Most victims (460,63\%) showed at least the presence of one of the several vulnerability factors investigated; the most common were a history of previous SV (26.7\%), a history of alcohol or other drugs abuse (20.4\%), and a past exposure to domestic violence or childhood maltreatment (19.2\%).

The perpetrator of SV was a known person in 395 cases (54\%), whereas in 292 cases (40\%) he was unknown to the victim. $44(6 \%)$ girls did not report their relationship with the perpetrator. In detail, the perpetrator was a friend or a schoolmate in 199 cases (30\%), a family member in 133 cases (18\%), and a current or former intimate partner in 53 cases (7.3\%). In 266 cases (36\%) the perpetrator of the SV was described by the survivors of SV as "a boy of the same age or in any case young", in 346 cases was described as an adult (47.3\%), in 13 cases as an elderly man (1,7\%), and in 106 cases this information was not reported by the victim (14.5\%). $120(16.4 \%)$ girls were sexually assaulted by more than one person at the same time. In only 3 cases the perpetrator of the SV was a woman.

359 (49.1\%) victims referred to SVSeD in the first 3 days after the SV occurred, 74 (10.1\%) between 3 and 7 days, 85 (11.6\%) between 7 and 30 days, and 188 (25.7\%) after 30 days. A statistically significant correlation between time passed from SV to admission in SVSeD and victims/perpetrators relationship was found $(P<0.00001)$ : if the perpetrator was an unknown person, the victim more frequently referred to SVSeD within 3 days from the assault, whereas if he was a family member, victims delayed their access to SVSeD after a month or even more.

\section{Characteristics of SV}

SV was associated with domestic violence in 108 cases (15\%), and was referred as a non-single episode of abuse by 206 victims $(30 \%)$. In about one third of the cases $(n=236,32.3 \%)$ the sexual assault occurred in a public place (streets or parks), in 146 cases $(20 \%)$ at the victim's place, in 168 cases $(23 \%)$ at the perpetrator's home. 
Table I Socio-Demographic Characteristics of the Population Under Study

\begin{tabular}{|l|l|}
\hline Age (M+SD): I5.5+2.4 Years & $\mathbf{n}(\%)$ \\
Range 10-13 & $155(21.2 \%)$ \\
Range 14-16 & $294(40.2 \%)$ \\
Range 17-19 & $282(38.6 \%)$ \\
Region of origin & $\mathbf{n}(\%)$ \\
Italy & $404(55.3 \%)$ \\
Latin America & $167(22.8 \%)$ \\
Eastern Europe and Russia & $84(11.5 \%)$ \\
Africa & $39(5.3 \%)$ \\
Another & $35(4.8 \%)$ \\
Missing data & $2(0.3 \%)$ \\
Vulnerability factors for SV & $\mathbf{n}(\%)$ \\
Previous sexual aggression & $195(26.7 \%)$ \\
Alcohol and other drug abuse & $149(20.4 \%)$ \\
History of pregnancies or abortions & $142(19.4 \%)$ \\
Exposure to domestic violence and/or child maltreatment & $140(19.2 \%)$ \\
& $76(10.4 \%)$ \\
Psychiatric or cognitive disorders & $69(9.4 \%)$ \\
Adoption/community housing & $47(6.4 \%)$ \\
Other factors & $98(13.4 \%)$ \\
\hline
\end{tabular}

Notes: ${ }^{a}$ Vulnerability factors are unknown for 150 victims; percentages are calculated on the total sample (731 victims). More than one factor could be present at the same time. 'Prostitution, homeless, physical disease involving disability, criminal record.

In $591(80 \%)$ cases the SV involved a genital and/or oral penetration with different modality (penis, fingers or other objects). We classified SV as "sexual assault with penetration" and "sexual assault without penetration". The relationship between the type of SV (with or without penetration) and several characteristics of the victims is reported in Table 2. Risk factors for SV involving penetration were: age $>14$ years, victims from Latin America, East Europe or Russia, alcohol or other drugs abuse, prostitution, criminal records (Table 2). A logistic regression analysis (dependent variable: penetration; independent variables: age, nationality, substance abuse, vulnerability factors) confirmed that age $>17$ years $(\mathrm{AOR}=2.4,95 \% \mathrm{CI} 1.4-4.1, P=0.006)$ and alcohol/other drug abuse (AOR=3.1 95\% CI 1.6-6.2, $P=0.01)$ are risk factors for SV involving penetration.

Of the 591 cases of SV with penetration, in 416 cases $(70 \%)$ the abuse consisted in a penile penetration, in 41 cases (7\%) in a finger penetration, in only 2 cases other objects were used and in the $22 \%$ of cases victims did not report this specific information. In 330 cases (45\%) there was a vaginal penetration. Exclusive anal/oral penetration was reported respectively by 17 and 15 victims (2\%), whereas a multiple penetration (vaginal/anal/oral) was reported by 78 victims (10.8\%). In only 17 cases (3\%) victims remembered use of condom by the perpetrator during the SV. 28 girls $(5 \%$ of victims with penile vaginal penetration) became pregnant because of the sexual assault.

\section{Characteristics of the Ano-Genital Lesions and of the Extra-Genital Lesions}

The presence and features of the ano-genital lesions due to the SV were analyzed only in victims who referred to SVSeD within the first 7 days after the violence, who reported any type of genital penetration and who gave consent to genital examination $(\mathrm{n}=354)$.

196 victims (55\%) presented at least one genital lesion. The different types of lesions (redness, abrasions, superficial or deep lacerations, bruising, bleeding) and the site of lesions (labia minora, labia majora, clitoris, external urethral meatus, posterior fourchette, perineal body, anus, hymen, vagina) were analyzed. Redness was the most frequent type of lesion $(56.5 \%)$, followed by hymenal lacerations $(18.9 \%)$. The most frequent seats of genital lesion were posterior fourchette $(37.6 \%)$, hymen $(18.9 \%)$ and labia majora (16.9\%). 
Table 2 Characteristics of Sexual Violence as Regard to Socio-Demographic Characteristics of Victims and Perpetrators

\begin{tabular}{|c|c|c|c|c|c|}
\hline & $\begin{array}{l}\text { Sexual Assault with } \\
\text { Penetration n (\%) }\end{array}$ & $\begin{array}{l}\text { Sexual Assault without } \\
\text { Penetration n (\%) }\end{array}$ & OR & $95 \% \mathrm{Cl}$ & $\boldsymbol{P}$ \\
\hline Total & 591 & 140 & & & \\
\hline \multicolumn{6}{|l|}{ Relationship with the perpetrator } \\
\hline Unknown & $238(40.3 \%)$ & $54(38.6 \%)$ & I & & \\
\hline Known & $323(54.7 \%)$ & $82(58.6 \%)$ & 0.8 & 0.6 to 1.3 & $P=0.56$ \\
\hline \multicolumn{6}{|l|}{ Missing data (34) } \\
\hline \multicolumn{6}{|l|}{ Victim's age } \\
\hline $10-13$ years & $105(17.8 \%)$ & $50(35.7 \%)$ & I & & \\
\hline $14-16$ years & $237(40.1 \%)$ & $57(40.7 \%)$ & 2.0 & 1.3 to 3.1 & $P=0.003$ \\
\hline $17-19$ years & $249(42.1 \%)$ & $33(23.6 \%)$ & 3.6 & 2.2 to 5.9 & $P<0.0001$ \\
\hline \multicolumn{6}{|l|}{ Missing data $(0)$} \\
\hline \multicolumn{6}{|l|}{ Region of origin } \\
\hline Italy n (\%): & $311(52.6 \%)$ & $93(66.4 \%)$ & I & & \\
\hline Latin America n (\%): & $143(24.2 \%)$ & $24(17.1 \%)$ & 1.8 & 1.0 to 2.9 & $P=0.02$ \\
\hline Eastern Europe and Russia n (\%): & $73(12.4 \%)$ & II (7.9\%) & 2 & I to 3.9 & $P=0.05$ \\
\hline Africa $n(\%)$ : & $32(5.4 \%)$ & $7(5.0 \%)$ & 2.0 & 0.7 to 5.3 & $P=0.2$ \\
\hline Other n (\%): & $30(5.0 \%)$ & $5(3.5 \%)$ & 1.4 & 0.6 to 3.6 & $P=0.4$ \\
\hline \multicolumn{6}{|l|}{ Missing data (2) } \\
\hline \multicolumn{6}{|l|}{ Vulnerability factors $^{\mathrm{a}}$} \\
\hline Absence of any factor $\mathrm{n}(\%)$ & $202(34.2)$ & $69(49.3)$ & I & & \\
\hline Previous sexual aggression n (\%): & $153(25.9)$ & $42(30 \%)$ & 1.2 & 0.9 to 1.9 & $P=0.32$ \\
\hline Alcohol and other drug abuse $\mathrm{n}(\%)$ : & I 38 (23.4\%) & II (7.9) & 4.3 & 2.2 to 8.4 & $P<0.000 I$ \\
\hline $\begin{array}{l}\text { Exposure to domestic violence and child } \\
\text { maltreatment } n(\%) \text { : }\end{array}$ & III (I8.8\%) & $29(20.7)$ & 1.3 & 0.8 to 2.3 & $\mathrm{P}=0.3$ \\
\hline Psychiatric or cognitive disorder n (\%): & 61 (10.3\%) & $15(10.7)$ & 1.4 & 0.7 to 2.6 & $P=0.3$ \\
\hline Adoption/community housing $\mathrm{n}(\%)$ & $58(9.8 \%)$ & II (7.9) & 1.8 & 0.9 to 3.6 & $P=0.1$ \\
\hline Previous pregnancies or abortions $\mathrm{n}(\%)$ : & $46(7.8)$ & I (0.7) & 15.7 & 2.1 to 116 & $P=0.007$ \\
\hline Other factors ${ }^{\mathrm{b}} \mathrm{n}(\%)$ : & $125(21.2 \%)$ & $17(12.1)$ & 2.5 & I. 4 to 4.4 & $P=0.002$ \\
\hline
\end{tabular}

Notes: ${ }^{a}$ The total is higher than 73 I due the contemporary presence, in some victim, of more than one factor. ${ }^{\mathrm{b}}$ Prostitution, homeless, physical disease involving disability, criminal record, etc.

As reported in Table 3, ano-genital lesions were classified into two categories, to better identify predictive factors for the presence of ano-genital injuries according to the characteristic of the SV. The chosen categories were: a) low-grade /aspecific lesions (redness); and b) high-grade lesions (abrasions, superficial or deep lacerations, bruising, bleeding). A logistic regression analysis confirmed that the absence of previous sexual intercourse, the occurrence of penile penetration and/or anal penetration were predictive factors for the presence of high-grade lesions, as intuitively supposed. There were no associations between any of the characteristics of the SV considered and the presence of low-grade /aspecific lesions. No other predictive factors for high-grade lesions were detected.

As regard to extra genital lesions, we considered the victims who referred to SVSeD within 7 days from the assault and who underwent a forensic examination. We could assess that, on a total of 362 cases, lesions were found in 202 victims (55.8\%). Ecchymosis or bruising were the most represented, accounting for about $60 \%$ of the lesions, followed by excoriations $(33.2 \%)$. Tears and burns were significantly less denoted $(4.4 \%$ and $0.4 \%)$.

In general, ie considering both genital and extra genital lesions, we evaluated the sample of victims referring within 7 days and who underwent both genital and forensic evaluation. Of the 335 adolescents studied, 259 (77\%) had at least a physical lesion in any body site. 
Table 3 Relationship Between Typology of Ano-Genital Lesions and Characteristics of the Sexual Violence ${ }^{\mathrm{a}}$

\begin{tabular}{|c|c|c|c|c|c|c|}
\hline & $\begin{array}{r}\text { Victims }^{b} \\
n(\%)\end{array}$ & $\begin{array}{r}\text { No Ano-Genital } \\
\text { Lesions n (\%) }\end{array}$ & $\begin{array}{r}\text { Low-Grade } \\
\text { Lesions n (\%) }\end{array}$ & $\begin{array}{r}\text { High-Grade } \\
\text { Lesions }^{c} \text { n (\%) }\end{array}$ & $\begin{array}{l}\text { AOR - 95\% Cl High } \\
\text { Grade vs No Lesions }\end{array}$ & $P$ \\
\hline \multicolumn{7}{|l|}{ Age } \\
\hline $10-13$ years & $38(10.7)$ & $19(12.0)$ & II (I7.5) & $8(6.0)$ & 1 & \\
\hline $14-16$ years & $139(39.3)$ & $59(37.3)$ & $22(34.9)$ & $58(43.6)$ & $2.3-0.9$ to 5.8 & 0.07 \\
\hline $17-19$ years & $177(50.0)$ & $80(50.6)$ & $30(47.6)$ & $67(50.4)$ & $2-0.8$ to 4.8 & 0.10 \\
\hline \multicolumn{7}{|l|}{ Region of origin } \\
\hline Italy & $191(54.0)$ & $83(52.5)$ & $37(58.7)$ & 71 (53.4) & 1 & \\
\hline Latin America & $76(21.5)$ & $39(24.7)$ & II (I7.5) & $26(19.5)$ & $0.8-0.4$ to 1.4 & 0.40 \\
\hline $\begin{array}{l}\text { Eastern Europe } \\
\text { and Russia }\end{array}$ & $48(13.6)$ & $16(10.1)$ & $10(15.9)$ & $22(16.5)$ & $1.6-0.8$ to 3.3 & 0.20 \\
\hline Another & $33(9.3)$ & $14(8.9)$ & $5(7.9)$ & $14(10.5)$ & I.2-0.5 to 2.6 & 0.70 \\
\hline \multicolumn{7}{|c|}{ Relationship with the perpetrator } \\
\hline Known & $155(43.8)$ & $73(46.2)$ & $24(38.1)$ & $58(43.6)$ & 1 & \\
\hline Unknown & $|7|(48.3)$ & $67(42.4)$ & $33(52.4)$ & $72(54.1)$ & $1.3-0.8$ to 2.1 & 0.20 \\
\hline \multicolumn{7}{|c|}{ Number of perpetrators } \\
\hline Single perpetrator & $255(72.0)$ & III (70.3) & $44(69.8)$ & $100(75.2)$ & 1 & \\
\hline Group violence & $67(18.9)$ & $30(19.0)$ & $12(19.0)$ & $25(18.8)$ & $0.9-0.5$ to 1.7 & 0.80 \\
\hline \multicolumn{7}{|c|}{ Previous sexual intercourses } \\
\hline Yes & $200(56.5)$ & $97(61.4)$ & $32(50.8)$ & 71 (53.4) & 1 & \\
\hline $\begin{array}{l}\text { First sexual } \\
\text { experience }\end{array}$ & $120(33.9)$ & $43(27.2)$ & $20(31.7)$ & $57(42.9)$ & $1.8-1.1$ to 3 & 0.02 \\
\hline \multicolumn{7}{|c|}{ Alcohol and other drug abuse } \\
\hline No abuse & $\mid 46(4 \mid .2)$ & $62(39.2)$ & $27(42.9)$ & $57(42.9)$ & 1 & \\
\hline Presence of abuse & $113(31.9)$ & $47(27.8)$ & $22(34.9)$ & $47(35.3)$ & $1.2-0.7$ to 2 & 0.60 \\
\hline \multicolumn{7}{|c|}{ Penetration modality } \\
\hline $\begin{array}{l}\text { Digital } \\
\text { penetration }\end{array}$ & $22(6.2)$ & $15(9.5)$ & $2(3.2)$ & $5(3.8)$ & $\mathbf{I}$ & \\
\hline Penile penetration & $239(67.5)$ & $97(61.4)$ & $38(60.3)$ & $104(78.2)$ & $3.2-1.1$ to 9.3 & 0.03 \\
\hline \multicolumn{7}{|c|}{ Site of penetration } \\
\hline $\begin{array}{l}\text { Vaginal } \\
\text { penetration }\end{array}$ & $204(57.6)$ & $90(57.0)$ & $33(52.4)$ & $81(60.9)$ & 1 & \\
\hline $\begin{array}{l}\text { Anal or ano- } \\
\text { vaginal } \\
\text { penetration }\end{array}$ & $45(12.7)$ & $14(8.9)$ & $5(7.9)$ & $26(19.5)$ & $2.0-1.0$ to 4.2 & 0.05 \\
\hline Total & 354 & 158 & 63 & 133 & & \\
\hline
\end{tabular}

Notes: ${ }^{2}$ Analysis were conducted only considering victims who presented to SVSeD within seven days from the sexual violence, who denounced a violence comporting any type of ano-genital penetration and who gave consent to genital examinations $(n=354)$. ${ }^{\mathrm{b}} \mathrm{Total}$ of victims is not always 354 , due to the presence of missing data. ${ }^{\mathrm{C}} \mathrm{High}$-grade lesions: abrasion, superficial tear, deep tear, bruise, bleeding, acute hymnal lesions, acute vaginal wall lesions. 


\section{Discussion}

The present retrospective study examines a large series of sexually abused female adolescents who referred to a public Italian anti-rape center. Findings confirmed that previous SV, alcohol or other drug abuse, and past exposure to domestic violence or childhood maltreatment were prevalent vulnerability factors for sexual victimization in adolescence, and that in more than half of cases the perpetrator of the sexual abuse was a known person. Moreover, the current research offers a broad overview on frequency, sites and types of genital lesions caused by the sexual abuse, helping clinicians to accurately define injuries related to the episodes of violence. These findings can be particularly useful for forensic purpose. To our knowledge, this is the largest study evaluating these specific characteristics related to SV against adolescent girls.

SVSeD is a public against violence center located in a referral university hospital, which offers health, social, psychological and legal support to women and children victims of sexual abuse and intimate partner violence. SVSeD, 24/7/365 opened, encompasses the presence of different continuously trained professional figures: gynecologists, forensic medical doctors, nurses, psychologists, social workers and lawyers, cooperating in a well-established, standardized, and comprehensive multidisciplinary approach. SVSeD standardized protocol of care involves the collection of social, medical, and psychological information, such as the presence of vulnerability factors of the victim, the description of the characteristics of the SV and of the perpetrator, the gynecological/physical examination guided by colposcopy recording the occurrence of genital/extra genital lesions, the assessment of psychological repercussions and the registration of swabs, blood and urine results for biological, toxicological and microbiological testing. A written consent for all these medical procedures is always requested.

Moreover, SVSeD offers psychological support to the victims of violence and even to their relatives if necessary. Healthcare professionals usually directly refer to the judicial authority, in the cases specified by the national against violence laws.

SVSeD is, both for other local hospitals and for judicial authority, the main referral center for SV of the city of Milan and hinterland, with a resident population of about three million of people. For this reason, we can assume that the SVSeD adolescent population is representative of the general population of sexual assaulted adolescents, allowing us to reasonably come to some conclusions, nevertheless the high level of submerged data.

In this research, we adopted the definition of adolescence developed by the WHO, ie girls between 10 and 19 years of age. Therefore, according to this definition, the great majority of adolescents are included in the age-based definition of "child", used by the Convention on the Rights of the Child, as a young under the age of 18 years. ${ }^{28}$

In our study, most adolescents ( $79 \%$ of the sample) were aged 14-19. This could partly explain why SV involving penetration (either oral, vaginal or anal) was very common in our sample, involving $80 \%$ of the total of the adolescent girls. However, a considerable percentage of girls under the age of 14 years referred SV involving some form of penetration (17.8\%), which is particularly alarming. Our results are similar to those reported by authors who studied adolescents and adult women victims of sexual abuse, showing that, in the majority of cases, sexual violence in adolescence involve acts of penetration. ${ }^{19-21}$ However, this finding could be due to the high frequency of unreported SV, in particular in an emergency context, if the abuse consists in non-penetrative acts. For this reason it should be interpreted cautiously, as it could be not fully representative of the totality of adolescent sexually abused girls.

The high prevalence of penetrative acts gives causes for concern, especially considering that some authors have suggested that children and/or adolescents victims of SV with penetration present a higher frequency of subsequent sexual risk behaviors compared to victims of non-penetrative sexual abuse, including more sexual partners, more contraction of sexually transmitted diseases, more unplanned pregnancies. ${ }^{13,29}$

According to the logistic regression performed, age $>17$ years and alcohol/other drug abuse are major risks factors for undergoing SV with penetrative acts. These findings are comparable to those of East and Hokoda, ${ }^{30}$ who have shown that early indicators of risky lifestyle such as sex, drug and alcohol abuse are associated with an increased probability of subsequent sexual victimization. Adolescents have demonstrated increased disclosure in reporting voluntary drug use associated with sexual assault if compared to the adult population. ${ }^{31}$ Seifert ${ }^{32}$ reported that alcohol or other drug use before a sexual assault has been referred by more than $40 \%$ of adolescent victims and adolescent perpetrators of SV. 
However, the association between sexual victimization and substance abuse is complex and often mutual, and it could be difficult to determine whether SV is the consequence or the reason of substance abuse. ${ }^{33}$ Besides all these considerations, the importance of a proper education on substances abuse in adolescence appears pivotal in terms of prevention.

Our research underlined that previous SV and past exposure to domestic violence or childhood abuse are major vulnerability factors for sexual (re)victimization, as similarly reported by other authors. ${ }^{34,35}$ Walker et al, conducted a meta-analysis on the prevalence of sexual revictimization, concluding that the prevalence of revictimization reached almost $50 \%$ of the cases. ${ }^{36}$ Other authors have underlined that female victims of childhood abuse are three to five times more likely to experience further SV than those who have not experienced sexual abuse in childhood. ${ }^{37}$

In our study, a considerable number of adolescent victims of SV reported past or concomitant exposure to domestic violence and/or child maltreatment (19.2\%) and previous sexual aggression (26.7\%). These findings appear particularly worrying, especially considering that repeated abusive experiences in adolescence may have cumulative devastating effects on cognitive development and global health, such as increased risk of reproductive dysfunctions, chronic pain, depression, anxiety, eating disorders, decreased school functioning, social adjustment problems, and even suicide attempts. ${ }^{14,25,37}$ Childhood sexual victimization is also reported to increase the individual's risk for later delinquent/ criminal behavior. Moreover, SV at young age is associated with an increased risk of arrest for sex crimes and/or for prostitution. $^{38}$

Frequently, SV through psychological or physical pressure occurs in dating relationship among adolescents. In these cases, girls may not be fully aware of the SV they are experiencing, with a high risk of normalization or trivialization of violence because of a cultural process involving misleading representations of love in movies, famous books, TV shows or music video, which may lead to a distorted perception of the violence itself. ${ }^{39}$ In our study a considerable percentage of SV (36\%) was perpetrated against adolescent girls by an adolescent boy or young adult, pointing out how teen dating violence could represent a major alarming health risk. Moreover, increased risk-taking behaviors such as contacts and relations with strangers through the Internet or social media cause additional risks to the adolescent population, including cyber dating victimization. ${ }^{40}$

All these factors together make the adolescence a period of extreme vulnerability to sexual abuse - both at home and outside the family - for several reasons. First, adolescent girls may frequently face unwanted and persistent sexual approaches as they gradually physically mature and begin to assume a defined sexual identity. Second, adolescents are usually very high-risk takers, requiring freedom from family rules and persistently searching for exploration and experimentation. However, many adolescents may have not yet developed the appropriate cognitive skills allowing them to correctly identify and elude potentially dangerous situations, at risk for sexual abuse. ${ }^{41}$ Several authors have investigated the role of targeted interventions based on school and community and addressing relationship skills, with the aim of preventing adolescent intimate partner violence, including physical, sexual, psychological violence, and/or sexual harassment. ${ }^{42-45}$ A systematic review published by De Koker et al ${ }^{46}$ concluded that these kinds of interventions, focused on key adults in the adolescents' environment, such as parents, teachers and community members, are effective in reducing perpetration of violence and victimization among adolescents.

Our research found that when penetrative SV was evaluated within the first week, 55\% of the sexually abused girls presented at least one genital lesion. A huge variability in frequency of genital lesions after SV is described in literature, with a rate ranging from $22.8 \%{ }^{47}$ to $87 \%{ }^{48}$ This variability may depend on several factors. For instance, timing and modality of gynecological examination (for example the use of colposcopy) and the expertise of the examiner are crucial in identifying genital lesions. In addition, the presence of genital lesions strongly depends on specific characteristics of victims, perpetrators, and modality of sexual assault. Moreover, there are inconsistencies among studies as regard clinical and anatomical classification of genital lesions caused by sexual abuse; some authors, for example, do not include genital redness in their analysis. ${ }^{49}$ Given these observations, and as already assessed by literature, ${ }^{49,50}$ it would be important to raise awareness among social workers, police officers, magistrates, and prosecutors of the limited role of genital lesions in confirming a sexual abuse, as the absence of any type of genital lesions does not contrast with the suspect of sexual victimization. However, a detailed and exhaustive description of genital lesions, if present - including pictures or videoscould be of great value for the success of the judicial process, and should be encouraged among healthcare professionals 
involved in the emergency care of sexually abused girls. This could be particularly important if one considers that, as described in our previous study, serological/DNA analyses were requested by the judicial authority in only 9/473 (1.9\%) of cases of sexual violence among adolescents. ${ }^{51}$ The cause of such infrequent use of genetic analysis in criminal proceedings regarding sexual violence in Italy is difficult to explain. Probably, as a result of practice and cultural factors, Italian public prosecutors are accustomed to relying mostly on traditional pieces of evidence such as oral witnesses, presence of physical lesions, and wiretappings. ${ }^{51}$ Similarly, we observed that magistrates or judges requested serological and/or DNA analyses in 86 out of $1211(7,1 \%)$ cases of sexual violence against adult women. ${ }^{52}$

The most important limitation of the current study is that the data were collected retrospectively from existing medical records. This methodology carries the typical limitations of recorded patient information, including high rate of unreported information and possible errors.

In conclusion, the evidence provided by the present study confirms that previous SV, alcohol or other drug abuse and past exposure to domestic violence or childhood maltreatment were important vulnerability factors for sexual victimization in adolescence, and that in more than half of cases the perpetrator of the sexual abuse was a known person. Moreover, findings underline the need for more effective public policies aimed at preventing SV in young girls, with a specific focus on the needs of the adolescent population. ${ }^{27}$

When an acute sexual assault occurs, victims should receive a medical evaluation as soon as possible, involving a forensic collection of all the anatomical and biological elements. Healthcare figures should have advanced and continuous training in the evaluation of the sexual assaulted victims and should fully collaborate with all the other professional figures involved in these cases, such as psychologists, social workers and lawyers. A prompt identification of sexual victimization may help reduce the risk of future major health problems and/or subsequent sexual victimization in adulthood.

\section{Disclosure}

The authors report no conflicts of interest for this work.

\section{References}

1. World Health Organization. World report on violence and health; 2002. Available from: http://apps.who.int/iris/bitstream/10665/42495/1/ 9241545615_eng.pdf. Accessed October 9, 2021.

2. Council of Europe. Convention on preventing and combating violence against women and domestic violence; 2011. Available from: https://rm.coe. int/168008482e. Accessed October 9, 2021.

3. World Health Organization. Child maltreatment; 2020. Available from: https://www.who.int/news-room/fact-sheets/detail/child-maltreatment. Accessed January 19, 2022.

4. Barker LC, Stewart DE, Vigod SN. Intimate partner sexual violence: an often overlooked problem. J Womens Health. 2019;28(3):363-374. doi:10.1089/jwh.2017.6811

5. World Health Organization. Understanding and addressing violence against women; 2012. Available from: http://apps.who.int/iris/bitstream/handle/ 10665/77432/WHO_RHR_12.36_eng.pdf?sequence=1. Accessed January 19, 2022.

6. Sapp MV, Vandeven AM. Update on childhood sexual abuse. Curr Opin Pediatr. 2005;17(2):258-264. doi:10.1097/01.mop.0000158731.64293.c7

7. ISTAT. La Violenza Contro le Donne Dentro e Fuori la Famiglia; 2015. Available from:https://www.istat.it/it/files/2015/06/Violenze_contro_le_ donne.pdf?title=Violenza+contro+le+donne+-+05\%2Fgiu\%2F2015+-+Testo+integrale.pdf. Accessed October 9, 2021.

8. Planty M, Langton L, Krebs C, Berzofsky M, Smiley-McDonald H. Female Victims of Sexual Violence. RTI International; 2013 : 1-17.

9. Rich M, Bar-on M. Child health in the information age: media education of pediatricians. Pediatrics. 2001;107(1):156-162. doi:10.1542/ peds.107.1.156

10. Crawford-Jakubiak JE, Alderman EM, Leventhal JM. Care of the adolescent after an acute sexual assault. Pediatrics. 2017;139(3):e20164243. doi: $10.1542 /$ peds.2016-4243

11. Bachman R. A comparison of annual incidence rates and contextual characteristics of intimate-partner violence against women from the National Crime Victimization Survey (NCVS) and the National Violence Against Women Survey (NVAWS). Violence Against Women. 2000;6(8):839-867. doi: $10.1177 / 10778010022182173$

12. World Health Organization. Global status report on violence prevention; 2014. Available from: https://www.who.int/publications/i/item/ 9789241564793. Accessed October 9, 2021.

13. Kashani JH, Shekim WO, Burk JP, Beck NC. Abuse as a predictor of psychopathology in children and adolescents. J Clin Child Psychol. 1987;16 (1):43-50. doi:10.1207/s15374424jccp1601_6

14. Patton GC, Sawyer SM, Santelli JS, et al. Our future: a Lancet commission on adolescent health and wellbeing. Lancet. 2016;387 (10036):2423-2478. doi:10.1016/S0140-6736(16)00579-1

15. Barbara G, Collini F, Cattaneo C, et al. Sexual violence against adolescent girls: labeling it to avoid normalization. J Womens Health. 2017;26 (11):1146-1149. doi:10.1089/jwh.2016.6161 
16. Rinne-Albers MA, Boateng CP, van der Werff SJ, et al. Preserved cortical thickness, surface area and volume in adolescents with PTSD after childhood sexual abuse. Sci Rep. 2020;10(1):3266. doi:10.1038/s41598-020-60256-3

17. World Health Organization. Guidelines for medico-legal care of victims of sexual violence; 2003. Available from: https://apps.who.int/iris/handle/ 10665/42788. Accessed January 19, 2022.

18. Lomax J, Meyrick J. Systematic Review: effectiveness of psychosocial interventions on wellbeing outcomes for adolescent or adult victim/ survivors of recent rape or sexual assault. J Health Psychol. 2020:305-331. doi:10.1177/1359105320950799

19. Grossin C, Sibille I, Lorin De La Grandmaison G, Banasr A, Brion F, Durigon M. Analysis of 418 cases of sexual assault. Forensic Sci Int. 2003;131(2-3):125-130. doi:10.1016/S0379-0738(02)00427-9

20. Blake de MT, Drezett J, Vertamatti MA, et al. Characteristics of sexual violence against adolescent girls and adult women. BMC Women's Health. 2014;14(1):15. doi:10.1186/1472-6874-14-15

21. Riggs N, Houry D, Long G, Markovchick V, Feldhaus KM. Analysis of 1076 cases of sexual assault. Ann Emerg Med. 2000;35(4):358-362. doi:10.1016/S0196-0644(00)70054-0

22. Larsen ML, Hilden M, Lidegaard Ø. Sexual assault: a descriptive study of 2500 female victims over a 10-year period. BJOG. 2015;122 (4):577-584. doi:10.1111/1471-0528.13093

23. Steele SJ, Abrahams N, Duncan K, et al. The epidemiology of rape and sexual violence in the platinum mining district of Rustenburg, South Africa: prevalence, and factors associated with sexual violence. PLoS One. 2019;16(1):e0216449. doi:10.1371/journal.pone.0216449

24. Tsur N, Katz C, Klebanov B. Peritraumatic pain in child sexual abuse: children's descriptions of pain as conveyed in their testimonies following child sexual abuse. J Interpers Violence. 2020:886260520958653. doi:10.1177/0886260520958653

25. Harner H Sexual violence and adolescents. National Online Resource Center Violence Against Women; 2003: 1-14. Accessed from: https:/vawnet. org/sites/default/files/materials/files/2016-09/AR_Adolescent.pdf. Accessed October 9, 2021.

26. Torazzi E, Merelli V, Barbara G, et al. Similarity and differences in sexual violence against adolescents and adult women: the need to focus on adolescent victims. J Pediatr Adolesc Gynecol. 2021;34(3):302-310. doi:10.1016/j.jpag.2020.11.018

27. Adams JA, Kellogg ND, Farst KJ, et al. Updated guidelines for the medical assessment and care of children who may have been sexually abused. J Pediatr Adolesc Gynecol. 2016;29(2):81-87. doi:10.1016/j.jpag.2015.01.007

28. United Nations. Convention on the rights of the Child; 2006. Available from: https://www.unicef-irc.org/portfolios/general_comments/GC7.Rev.1_ en.doc.html. Accessed October 9, 2021.

29. Senn TE, Carey MP, Vanable PA, Coury-Doniger P, Urban M. Characteristics of sexual abuse in childhood and adolescence influence sexual risk behavior in adulthood. Arch Sex Behav. 2007;36(5):637-645. doi:10.1007/s10508-006-9109-4

30. East PL, Hokoda A. Risk and protective factors for sexual and dating violence victimization: a longitudinal, prospective study of Latino and African American adolescents. $J$ Youth Adolesc. 2015;44(6):1288-1300. doi:10.1007/s10964-015-0273-5

31. Negrusz A, Juhascik M, Gaensslen RE Estimate of the incidence of drug-facilitated sexual assault in the U.S; 2005. Available from: https://www. ncjrs.gov/pdffiles1/nij/grants/212000.pdf. Accessed October 9, 2021.

32. Seifert S. Substance use and sexual assault. Subst Use Misuse. 1999;34(6):935-945. doi:10.3109/10826089909037250

33. Dawgert S. Substance use and sexual violence: building prevention and intervention responses; 1999. Available from: http://www.pcar.org/sites/ default/files/pages-pdf/substance_use_and_sexual_violence.pdf. Accessed October 9, 2021.

34. Amstadter AB, Elwood LS, Begle AM, et al. Predictors of physical assault victimization: findings from the National Survey of adolescents. Addict Behav. 2011;36(8):814-820. doi:10.1016/j.addbeh.2011.03.008

35. Trotman GE, Young-Anderson C, Deye KP. Acute sexual assault in the pediatric and adolescent population. J Pediatr Adolesc Gynecol. 2016;29 (6):518-526. doi:10.1016/j.jpag.2015.05.001

36. Walker HE, Freud JS, Ellis RA, Fraine SM, Wilson LC. The prevalence of sexual revictimization: a meta-analytic review. Trauma Violence Abuse. 2017;20(1):67-80. doi:10.1177/1524838017692364

37. Stockman JKJ, Lucea MMB, Campbell JCJ. Forced sexual initiation, sexual intimate partner violence and HIV risk in women: a global review of the literature. AIDS Behav. 2013;17(3):832-847. doi:10.1007/s10461-012-0361-4

38. Pereda N, Abad J, Guilera G. Lifetime prevalence and characteristics of child sexual victimization in a community sample of Spanish adolescents. J Child Sex Abus. 2016;25(2):142-158. doi:10.1080/10538712.2016.1123791

39. Widom CP, Ames MA. Criminal consequences of childhood sexual victimization. Child Abuse Negl. 1994;18(4):303-318. PMID: 8187016. doi:10.1016/0145-2134(94)90033-7

40. Bonomi AE, Altenburger LE, Walton NL. "Double Crap!" Abuse and harmed identity in fifty shades of grey. J Womens Health. 2013;22 (9):733-744. doi:10.1089/jwh.2013.4344

41. Montiel I, Carbonell E, Pereda N. Multiple online victimization of Spanish adolescents: results from a community sample. Child Abuse Negl. 2016;52:123-134. doi:10.1016/j.chiabu.2015.12.005

42. American College of Obstetricians and Gynecologists. ACOG educational bulletin: adolescent victims of sexual assault. Number 252, October 1998. Int J Gynecol Obstet. 1999;64:195-199.

43. Foshee VA, Bauman KE, Ennett ST, Suchindran C, Benefield T, Fletcher Linder G. Assessing the effects of the dating violence prevention program "safe dates" using random coefficient regression modeling. Prev Sci. 2005;6(3):245-258. doi:10.1007/s11121-005-0007-0

44. Wolfe DA, Crooks C, Jaffe P, et al. A school-based program to prevent adolescent dating violence: a cluster randomized trial. Arch Pediatr Adolesc Med. 2009;163(8):692-699. doi:10.1001/archpediatrics.2009.69

45. Jaycox LH, McCaffrey D, Eiseman B, et al. Impact of a school-based dating violence prevention program among latino teens: randomized controlled effectiveness trial. $J$ Adolesc Health. 2006;39(5):694-704. doi:10.1016/j.jadohealth.2006.05.002

46. De Koker P, Mathews C, Zuch M, Bastien S, Mason-Jones AJ. A systematic review of interventions for preventing adolescent intimate partner violence. $J$ Adolesc Health. 2014;54(1):3-13. doi:10.1016/j.jadohealth.2013.08.008

47. McLean I, Roberts SA, White C, Paul S. Female genital injuries resulting from consensual and non-consensual vaginal intercourse. Forensic Sci Int. 2011;204(1-3):27-33. doi:10.1016/j.forsciint.2010.04.049

48. Slaughter L, Brow CR. Colposcopy to establish physical findings in rape victims. Am J Obstet Gynecol. 1992;166(1):83-86. doi:10.1016/00029378(92)91834-W 
49. Zilkens RR, Smith DA, Phillips MA, Mukhtar SA, Semmens JB, Kelly MC. Genital and anal injuries: a cross-sectional Australian study of 1266 women alleging recent sexual assault. Forensic Sci Int. 2017;275:195-202. doi:10.1016/j.forsciint.2017.03.013

50. Barbara G, Collini F, Cattaneo C, Facchin F, Vercellini P, Kustermann A. Sexual violence against adolescent girls: the need for shared multidisciplinary prevention strategies. BJOG. 2017;124(3):434. doi:10.1111/1471-0528.14409

51. Piccinini A, Vignali G, Bailo P, et al. Management of DNA evidence collected on adolescents in sexual assault investigations: a 10-year review from a large Italian rape centre. Med Sci Law. 2019;59(4):232-239. doi:10.1177/0025802419858538

52. Piccinini A, Bailo P, Vignali G, et al. How many DNA analyses are performed on adult sexual assault victims in Milan (Italy): a ten-year review. Forensic Sci Int Genet Suppl Ser. 2019;7(1):164-166. doi:10.1016/j.fsigss.2019.09.064

International Journal of Women's Health

\section{Publish your work in this journal}

The International Journal of Women's Health is an international, peer-reviewed open-access journal publishing original research, reports, editorials, reviews and commentaries on all aspects of women's healthcare including gynecology, obstetrics, and breast cancer. The manuscript management system is completely online and includes a very quick and fair peer-review system, which is all easy to use. Visit http://www. dovepress.com/testimonials.php to read real quotes from published authors.

Submit your manuscript here: https://www.dovepress.com/international-journal-of-womens-health-journal 